\title{
LINKING SUSTAINABLE TRANSPORT AND COMMUNITY DEVELOPMENT: TRANSPORTATION 2.0 IN THE SMALL ISLAND OF TOBAGO
}

\author{
Julia R. Kotzebue ${ }^{1^{*}}$ \\ ${ }^{1}$ Institute of Geography, Faculty of Food and Agriculture, \\ The University of the West Indies, Trinidad \\ ${ }^{1}$ Email: mail@julia-kotzebue.de *(Corresponding author)
}

\begin{abstract}
Worldwide the UN is promoting sustainable transport that requires the engagement of communities to make it context and community sensitive. To better engage the community, governments started to use web-based social geocommunication tools in urban areas. The use of these tools is increasing; however, it can be critically questioned to what extent they can support sustainable transport development in rural areas in Trinidad and Tobago. To respond to this question, the paper presents preliminary results of an ongoing pilot study in Charlotteville Tobago. The paper suggests an analytical framework to investigate the spatial governance process that is linked to the sustainable transport solution development. Results reveal that the majority depends on sharing mobility, which already is more environmentally friendly than individual car use. However, the digital literacy in the village is low which hampers the capacity to participate in an increasingly digitizing society.
\end{abstract}

Keywords: Sustainable transport, Community-building, Social geocommunication, Spatial governance.

https://doi.org/10.47412/AABL1209

\section{Introduction}

On the first United Nation's (UN) Global Sustainable Transport Conference, in 2016, the participating governments committed to "enhancing the role of sustainable transport in connecting people and communities to jobs, schools and health care and in the delivery of goods and services to rural and urban communities, thus providing all with equal opportunities and leaving no one behind" [1]. Although communities are in the centre of the mentioned commitment, they rarely participate in transport development in Trinidad and Tobago. One explanation for this phenomenon may originates in the idea of sustainable transport itself. Many sustainable transport concepts focus on the individual mobility needs [2-4]. This focus implies that an individual makes a choice in its own interests and strive to satisfy the own transport needs in first place [5].

Nonetheless, scholars also argue that the focus on personal needs and spatially car-oriented towns have facilitated the process of an individualistic society with increasing residential mobility and less social participation and mutual support $[6,7]$. At the same time transport is important to keep and develop social networks and the community [8,9]. Sociological transport concepts like mobility, highlight the potential for movement, the experience of people moving as well as the social-cultural impacts of movements between places in space [7, 10]. This shows the ambiguous effects of transport development on the community. 
A second stressed reason for the neglect of communities in transport development in Trinidad and Tobago is a lack of a holistic transport planning and an integrated sustainable transport and mobility governance. The National Internal Transportation Policy of 1996 is outdated and lacks orientation towards an integrated sustainable transport development [11]. The centralistic projectbased transport policy, solutions and planning mainly rest on projections of the economic and demographic development, population density, projections of traffic counts, as well as comparisons of the forecasted traffic volumes with the existing capacity.

It is assumed that the two highlighted reasons are important causes for the path dependency of the individualistic and motorized oriented transport development, which hampers Trinidad and Tobago's ability in transitioning towards sustainable transport development. Sustainable transport development here has a broader meaning than the technical transport planning; it includes solution finding, planning, implementation and management. This process involves several governmental actors from different ministries and diverse non-governmental stakeholders. The complexity of the process makes it difficult to fully plan or foresee the outcome, so that sustainable transport development can be better conceived as a spatial governance process. The spatial governance concept stresses the interaction of involved actors and the coordination of spatial development processes across policy silos, administrative and spatial boundaries [12, 13]. Understanding sustainable transport development as a common and continuously process, increase the need to engage the community.

To facilitate a better community involvement, several cities in Europe and the United States of America have started to use community mapping, in which community members can create their own maps and use existing web-based social geo-communication tools to participate in a sustainable transport planning. For instance, the Westminster Transportation and Mobility Plan and the city of Hamburg use web-based interactive mapping to visualize spatially and locate transport needs, ideas, mobility modes, sharing mobility facilities and inclusion of urban green. Communities can rate ideas and pass comments, so that decisions are not just on grounded on individual transport needs but also on economical and technical parameters $[14,15]$. Although software tools and smartphone apps encourage crowdsourced and community mapping in urban areas, the method is new in transport development in villages and in small islands. The paper therefore investigates to what extent the use of web-based social geo-communication tool supports the sustainable transport solution finding and community building in Tobago.

To respond to the question, the paper will discuss the preliminary findings of an ongoing pilot study in Charlotteville, Tobago. Initially, the paper briefly outlines the general transport situation in Trinidad and Tobago, and particular the impacts on the community in Charlotteville. This describes the governance and socio-cultural framework. Subsequently, this work introduces a theoretical framework that enables a systematic analysis of the spatial governance process in the sustainable transport solution development. Finally, the paper will link the first preliminary results of the study to the analysis.

\section{The Inner Transport System and the Community}

\subsection{The Inner Transport System}

Trinidad and Tobago has in common with other small island states that the inner transport development and system differ from continental urban and rural transportation systems, partly due to the specific isolated geographical position. The twin-island nation, like many small island states 
in the Caribbean, share a history of colonialism that resulted in transportation system, which was not systematically planned for the entire island. Instead, the transport system was developed in an ad hoc way for specific purposes, for instance ports and links for the former plantation based economy and later links for tourist resorts and shopping centres $[11,16]$.

The small domestic transport market with relatively small volumes of transport, a limited ability of an economy of scale, created relatively high transport costs. Transport development and investments are mainly dependent on governmental and non-governmental organisations like the Development Bank of Latin America [17]. The public transportation system is state-owned, underequipped, under-financed, and deficient. The Public Transport Service Cooperation partly operates without an approved strategic plan, and while wages and salaries have been continuously increased, the fare system remained unchanged since 1990. Despite the relative low fares, free ridership to schoolchildren and citizens over 60, the numbers of passengers are continuously dropping, e.g. from 12.6 million in 2010 to 7.6 million in 2014. The Cooperation is unable to service all routes and passengers and to be on schedule [18]. Thus, cars and maxi-taxis, became the major mode of transport. At the same time, the government constantly increased fuel subsidies since its introduction in the 1970s, although it disproportionally supports high income groups [19]. This resulted in very low fuel prices, and a high dependency on car ownership. Cars are also conceived as important status symbols that provide a sense of freedom and superiority to many island citizens [20]. Accordingly, the transport and urban development policy has favoured the infrastructure for individual motorized transport modes that decreased the walkability and bikeability in Trinidad and Tobago.

\subsection{The Transport System in Charlotteville}

Charlotteville is a remote area. Like other rural areas in Trinidad and Tobago it is far from a larger urban centre and have a relatively low accessibility to vital services. One major reason for this isolation is due to the concentration of Trinidad and Tobago`s population in small centres with a single larger urban centre. The road capacity is concentrated and directed towards few core locations, and vital services such as schools, workplaces, and health services are only accessible by car [21]. This is well exemplified by Charlotteville as shown in "Fig 1". The village, with its 863 permanent residents can be accessed through a main road that is partly too narrow for public transport buses [22]. Private owned non-fixed scheduled mini buses, so called maxi-taxis that seat 9 to 25 passengers, operate in Tobago. However, the Maxi-Taxi Act does not specify exact routes in Tobago, so that owners serve the most beneficial routes [23]. Accordingly, peripheral areas like Charlotteville are less frequently served. The infrastructure and transport system created rural areas that are geographically and socially relatively isolated.

With regard to the walkability and bikeability, although many people in Charlotteville walk short distances to the available vital facilities, such as the library and the primary school, the walkability is decreasing. Walkability can be understood as the degree of a favourable built environment to walking [24]. Bicycling facilities are lacking and few ride a bike in Charlotteville. 
Nonetheless, the low built-up speed favours the natural environment. Charlotteville is located at the edge of the Main Ridge Forest Reserve, a designated UN World Heritage Area on the northeastern top of Tobago. Additionally, the government proposed a North East Tobago Marine Protected Area in 2019, so that Charlotteville will be located in a land and marine protected area "Fig. 1" The special location has implication for the current transport situation and future transport planning. Sustainable transport planning cannot have a solely technical and economical approach but must take into account spatial and social realities. This means, the transport system has to

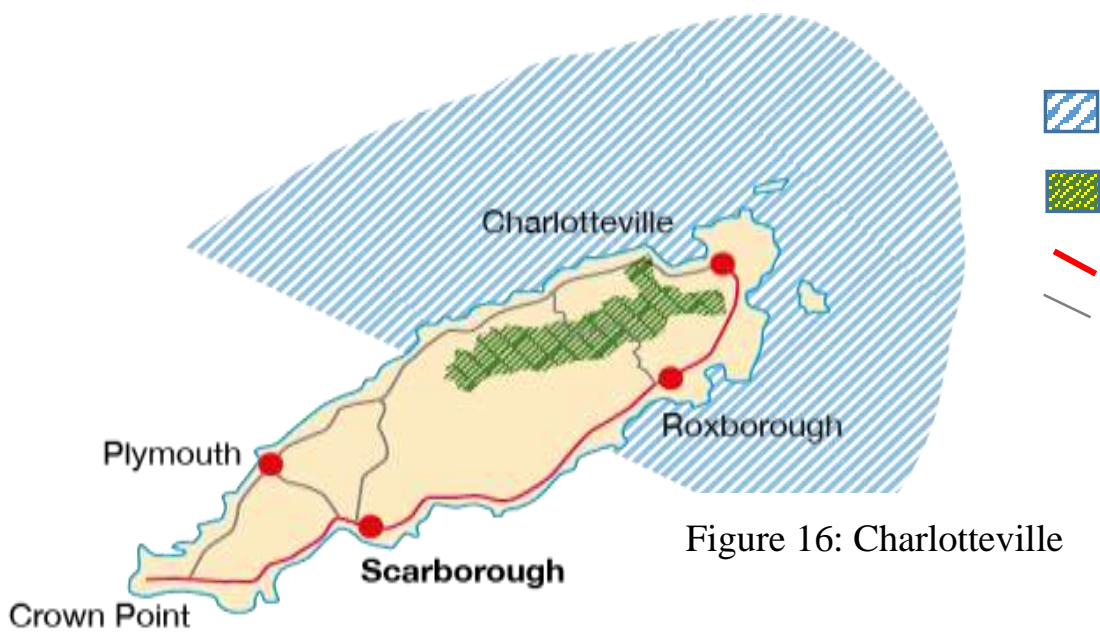

become more context and community sensitive. The next section will discuss community-building and social geo-communication in this context.

\section{Community-Building, Social Geo-Communication and Spatial Governance}

Although, the concept of community is widely used and central to community-sensitive transport development, the word is debated. I use it in a geographical and social setting that implies a sense of belonging to an area and a social structure [25]. Community often suggests a homogeneous social group but in reality, they are diverse. Nonetheless, the feeling of belonging, the so-called sense of community is important for participation and integration [26]. A strong sense of community is conceived as being beneficial for community-building, and vice versa [27]. Community-building can be understood as an activity that foster solution finding, and positive connections among organizations, groups, and individual community members [28].

As mentioned, the creation of context and community sensitive transport solutions highly depends on the participation of the community. The concept combines two ideas, context-sensitive solution development that stress the collaboration of transport developers, stakeholders and communitysensitivity. It seeks for transportation projects that fit in the physical -spatial, socio-cultural, economic, and environmental context [29,30]. The term community-sensitive refers to core elements of a community, the relationship with the spatial context, shared functions and norms, interpersonal relationships and social diversity e.g. gender and socio-economic status [31].

To better engage the community, web-based social geo-communication tools became increasingly used. Social geo-communication combines social media with geographic information systems, e.g. geo-media [32, 33]. Software tools and smartphone apps for voluntary crowd-sourced mapping have been increased [34]. It is assumed that social geo-communication empowers the community 
and allows participation. Hence, the use of social geo-communication tools can contribute to community-building. Community mapping indicates a link between map-creation and policymaking. The ability to produce, understand, critically think, reflect on submitted information can be therefore understood as a form of democratic and a kind of Spatial Citizenship [33].

Involving the community in the development of sustainable transport solution means including more actors than the Ministry of Transport and construction companies in the process. Furthermore, it is not purely community-based or enforced by the government, but an interaction of actors and the spatial-social context. Therefore, it can be conceived as a spatial governance process, which understanding is important for the response to the research question. The next section introduces an analytical framework that allows to simplify the process without ignoring the complexity.

\subsection{An Analytical Spatial Governance Framework and Social Geo-Communication}

The concept of spatial governance lacks a universally accepted definition. Several scholars describe it as the interplay, the actions and the relationship of governmental and non-governmental actors steering the appreciation, the organisation, the use and functions, the appearance of space and place across multiple spatial scales and administrative boundaries [12]. Institutions, informal policies and several context-dependent and non-linear process phases influencing spatial governance [35]. Accordingly, every spatial governance process is context dependent and unique. Concerning community and context-sensitive sustainable transport development, the heterogeneity and the trans-sectoral character makes it difficult to forecast the outcome of such process. For instance, the field of policy implementation have revealed dozens of variables, which are potentially relevant for the outcome of a policy and planning [36, 37]. Hence, instead of trying to investigate all potential variables that could shape the interaction of space and actors, it is helpful to use an analytical framework that focus on the key characteristics of space and key actors [38].

The spatial governance framework differentiates between first, the steering actors and their core characteristics: cognitions, motivations, and capacities "Fig. 2". According to Bressers these core characteristics are influential for many governance processes [39]. For instance, it is decisive for the outcome how participants and stakeholder understand their own built-up and natural environment. It is also important to recognise their motivation for participation or nonparticipation. Especially for the community-building, it is crucial that the engaged community members are aware about their own capabilities to reach their goals and to steer the process. 


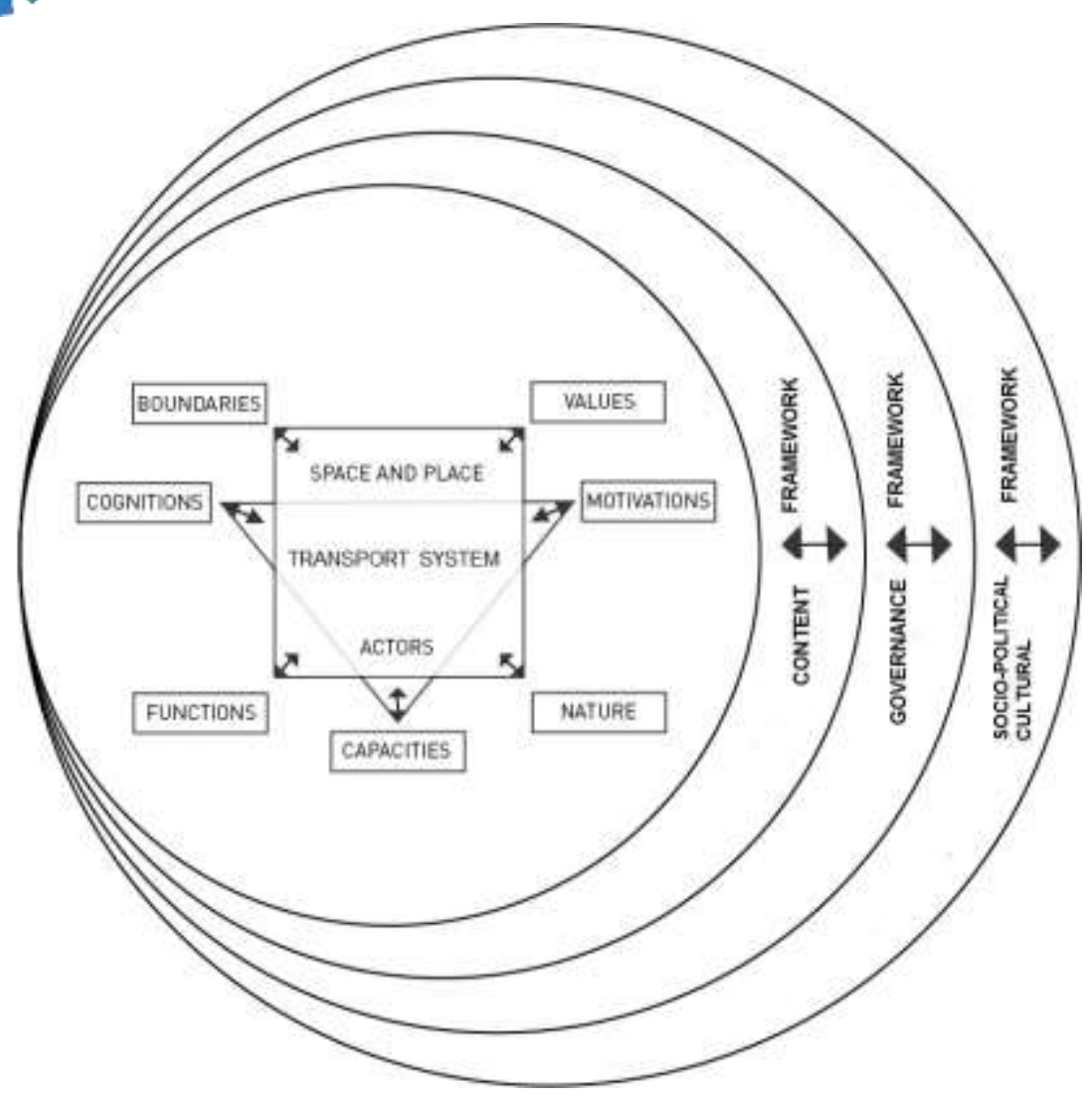

Figure 2: Spatial governance framework

Second, the analytical framework emphasize space and place with its key characteristics: institutional and spatial boundaries, cultural, and other values, functions, and nature. Space is not purely understood as the physical space but as social construct in the sense of place, which is linked to the self-identification of people with space [40, 41]. It is assumed that the actor's core characteristics and the spatial core characteristic mutually influential. Context-sensitive means a better integration of geographical factors in governance processes. For instant, scholars argue that geographical and administrative boundaries cause spatial exclusions, as studies showed that institutions, law, and regulations can "misfit" with spatial realities, which hampers an integrated and sustainable development $[38,42]$. It is also recognized that changing conceptions of mobility enable shifts in spatial governance [43].

The spatial governance process however is not only embedded in a spatial context but also influenced by a wider social framework. It is less flexible than the actor and place characteristics, and is often difficult to change in short-term. The entire framework can be analytically divided in three frameworks. First, the content framework that refers to key themes, concepts, and goals that steer the process, e.g. the UN Sustainable Development Goals and the government's development Vision 2030. Second, the governance framework, which refers to the existing governmental structure. Third, the socio-political and cultural framework that describes the existing culture, political system and social realities. 
With regard to the use of social geo-communication tools, it is assumed that they influence the key characteristics of the actors and place, and vice versa. On the one hand, crowdmapping and the visualization of place values, creates a reality that might influence the cognition of actors. On the other hand, the tools can highlight values of communities, which might overlooked in other methods. The method might also unveil multi-functionality of places and mismatches between official project boundaries and conceived boundaries. Nonetheless, concerning the capacities of actors, a prerequisite for the use of web-based social geo-communication tools is that users have a level of digital literacy, the ability to access, evaluate and create information with digital tools [44]. This means not merely the availability of information and the accessibility are decisive for the motivation to participate in the transport development process but also the ability to use the World Wide Web as a participation platform. The next section presents the first preliminary results of the pilot project in Charlotteville.

\section{Preliminary results}

The preliminary results are based on three unstructured interviews with community members, an ongoing online survey about sustainable transport, and the sense of community, as well as observations from two workshops. The survey was responded by 28 participants, thus approximately $3 \%$ of the permanent population of Charlotteville until to date. This rate is acceptable, considering the fact that comparable surveys in urban areas with regard to sustainable transport planning, often merely reach 1 or 2 percent of the population [14]. The participants were randomly selected, $50 \%$ of the responded were men and $43 \%$ female. The survey demographically matches with the permanent residents of Charlotteville as 51\% are male and $49 \%$ female [22]. Although general indicators are missing to measure sustainable transport and a sense of community, it is assumed that key indicators are valid.

\subsection{The Sense of Community}

As mentioned before, it is assumed that a strong sense of community enhances participation and community-building. Four elements are continuously mentioned in studies about the sense of community, so that it can be assumed that they are essential [26]. First, membership that refers to belonging, personal investment in the community and shared boundaries. Second, influence that corresponds with the perception that someone can participate, control and mutually affects the community. Third, integration that includes shared connections, shared events, history, and a positive sense of togetherness. Fourth, fulfilment of individual and group needs describes the benefits and assets that community members have because of being part.

\subsubsection{Membership}

The criteria membership gives information about the people, who belong to a community [45]. In the survey, we asked participants to indicate their core value towards the community. The survey revealed that $29 \%$ of the respondents consider the cooperation and the support of others as well as the togetherness as core value.

\subsubsection{Influence}

Influence is linked to steering and controlling, which is related to leadership. The concept of leadership can refer to both individual and collective actions [46]. How leadership is carried out, 
is context and community dependent [47]. In line with the assumption that leadership is decisive for the community, $22 \%$ of the participants stated that good leadership, especially the community council is a necessity for the community. With regard to an individual's capacity to influence the community, $10 \%$ of the respondents had no idea of what changes they could make to the transportation situation in Charlotteville.

\subsubsection{Integration}

McMillan and Chavi stated that heterogeneous communities in particular, need ceremonies, rituals, and symbols in order to unify and to develop a sense of community. According to $39 \%$ of the participants, the most important cultural event that requires preservation in Charlotteville, is the yearly Heritage Festival. For $28 \%$ of the respondents it is important to support other community members. Additionally, $10 \%$ of the respondents indicated that common achievements, sporting events and "liming", which can be described as a planned or spontaneous get-together for the purposes of relaxing, talking, or simply doing nothing is also important to the community [48]. Furthermore, fishing that was indicated by $18 \%$ and farming, mentioned by $10 \%$ of the respondents were considered to be important cultural activities.

\subsubsection{Fulfilment of Needs}

Finally, important for the engagement and the willingness of community members to participate is that they benefit from the community. The participants had been asked in the survey what the community does for them and why it is beneficial to be a member. To that question, $35 \%$ of the respondents stressed that no one from the community is doing anything beneficial for them.

\subsection{Sustainable Transport}

General accepted indicators to measure sustainable transport are lacking. Studies on indicator development and assessment are mainly focused on urban transport development. There are also no sustainable transport indicators for Trinidad and Tobago or the Caribbean region. Accordingly, the indicators for the pilot study are key indicators, drawn from sustainable transport literature [49, 50]. The survey assessed the following aspects: the behaviour, the mode of transport, and the "quality of sustainable transport" Furthermore, community members had been asked to identify the foremost aspects of sustainable transport.

\subsubsection{Modal Split and Transport Behaviour}

The survey revealed that the major mode of transport for the majority (62\%) is the maxi-taxi. The second main mode of transport is hitch-hiking (32\%), in the sense that a car owner gives paid or unpaid lift to someone else. Merely $30 \%$ of the participants said that they own a car. It is observed that many people walk short distances in Charlotteville but the respondents overlooked walking as a mode of transport. As described before bicycling is also not conceived as transport mode as $3 \%$ indicated that they use the bike frequently.

\subsubsection{Sustainable Transport Indicators}

The participants were allowed to select multiple answers with regard to the importance of sustainable transport factors. Accordingly, Table 1 shows that the majority indicated reliability, 
safety, comfort, and traveling time as the most important factors for sustainable transport. Environmental friendliness was rated as least important.

Table 8:Results sustainable transport.

\begin{tabular}{|l|l|}
\hline Transport indicator & Importance in percent \\
\hline Reliability & $68 \%$ \\
\hline Safety & $50 \%$ \\
\hline Comfort & $46 \%$ \\
\hline Traveling Time (fast) & $46 \%$ \\
\hline Availability & $43 \%$ \\
\hline Efficiency & $43 \%$ \\
\hline Variability (different modes of transport) & $43 \%$ \\
\hline Affordability (Cost saving) & $39 \%$ \\
\hline Healthy & $35 \%$ \\
\hline Accessibility & $35 \%$ \\
\hline Environmental friendliness & $32 \%$ \\
\hline
\end{tabular}

\subsection{The Use of Web-Based Social Geo-Communication}

Considering the use of social geo-communication in the village, the survey was offered online. The community had been informed via posters, e.g. in the library, the shops, and via personal contact. Nonetheless, lone person completed the survey online. Most village residents, when asked personally refused to complete the online survey. In comparison, when the same survey was printed on paper many of the asked residents agreed to participate. With regard to the use of the online mapping tool, the participants of the two workshops missed skills to use a mapping instrument, like google maps. Nonetheless, the participants liked the tool for visualization and rose some questions, but no one so far participated in the mapping.

\section{Discussion and Conclusion}

The paper highlights the issues of sustainable transport, spatial participation by the means of webbased social geo-communication, and community development in Charlotteville in Tobago. It aimed to assess the scope of support that the use of web-based social geo-communication in the sustainable transport solution finding and community building can provide. To systematically analyse the process, a spatial governance framework had been introduced. According to the framework, the key characteristics of place (boundaries, values, nature, functions) and actors (cognitions, motivations and capacities) are decisive for sustainable transport solutions. Due to the status of the project, the research yield merely preliminary results.

Important key characteristics of actors are cognitions and capacities, thus how participants understand and use the available information. With regard to the web-based mapping that was introduced in the two workshops, the participants did not use it so far. The preliminary results of the ongoing survey of the pilot project show that the community has a poor digital literacy. This limits the capacity to participate in a web-based process for sustainable transport development solutions. Furthermore, due to the low understanding, there is little motivation to use available 
web-based tools. The survey shows that as soon as the same information is presented on paper, the motivation to participate increase.

Furthermore, with regard to the place characteristics nature and values, the community has a limited understanding that transport needs to be environmentally friendly. For the majority the reliability of the transport mode is crucial. However, most residents use maxi-taxis and share cars, which is already environmentally friendly. Therefore, a goal of the project must be to further improve this behaviour and to avoid an increase in individual motorized transport.

Concerning the motivation of actors to develop sustainable transport solutions for the village, the sense of community is important. The survey reveals that $29 \%$ of the respondents consider cooperation as an important value. However, $35 \%$ percent mentioned that the community is doing nothing for them, which indicates little integration and willingness to do something for the community. All this can be understood as signal of a low sense of community. Accordingly, community members will have a low motivation to collaborate and to develop sustainable transport solutions.

Considering the capacities of the community members to influence the spatial governance process in sustainable transport. Supported by observations from the two workshops, it became clear that many community members consider transport as a clear governmental task. Additionally, 22\% from the participants of the survey expressed the need for a good community council. This can be interpreted in two ways. On the one hand, many community members are unconscious that they might have the capacity to change the status quo. On the other hand, the description of the governance and socio-cultural framework highlighted that a sustainable transport policy is lacking. Hence, the participants of the research project are might looking for guidance.

To conclude, it is too early to respond fully to the question because the community must first learn to use the web-based mapping tool. The study shows that with increasing digitalisation, rural communities can become even more socially and spatially isolated because of the lacking capacities to participate in the digital world.

\section{References}

[1] UN. 2016. Ashgabat statement on commitments and policy recommendations of the Global Conference on Sustainable Transport. In United Nations.

[2] P.L. Schiller, J.R. Kenworthy, 2018. An introduction to sustainable transportation: Policy, planning and implementation, Routledge, Oxon.

[3] J.-P. Rodrigue, C. Comtois, B. Slack, 2016.The geography of transport systems, Routledge, Oxon.

[4] EUcom, 2009. A sustainable future for transport, European Union, Luxembourg.

[5] E.J. Van De Kaa. Prospect theory and choice behaviour strategies: review and synthesis of concepts from social and transport sciences. European Journal of Transport and Infrastructure Research 10, (2010).

[6] J. Urry. Mobility and proximity, Sociology 36, (2002) 255-274.

[7] S. Barr, J. Prillwitz, T. Ryley, G. Shaw, 2017. Geographies of transport and mobility:

Prospects and challenges in an age of climate change, Routledge, London. 
[8] A. Busch-Geertsema, M. Lanzendorf, H. Müggenburg, M. Wilde, 2016.Mobilitätsforschung aus nachfrageorientierter Perspektive: Theorien, Erkenntnisse und Dynamiken des Verkehrshandelns, in: Handbuch Verkehrspolitik, Springer, Wiesbaden pp. 755-779.

[9] T. Schwanen, K. Lucas, N. Akyelken, D.C. Solsona, J.-A. Carrasco, T. Neutens. Rethinking the links between social exclusion and transport disadvantage through the lens of social capital. Transportation Research Part A: Policy and Practice 74, (2015) 123-135.

[10] J. Larsen, J. Urry, 2016. Mobilities, networks, geographies, Routledge, London.

[11] GovTT. 1996. National internal transportation policy. In Ministry of Works and Transport 1996.

[12] J. Westerink- Petersen, 2016. Making a difference: Boundary management in spatial governance, in, Wageningen University, Wageningen.

[13] J. Heley. Soft spaces, fuzzy boundaries and spatial governance in post-devolution Wales. International Journal of Urban and Regional Research 37, (2013) 1325-1348.

[14] HAM. 2019. Frohmestrasse. In Bezirksamt Eimsbüttel.

[15] WEST. 2019. Westminster Forward. In Westminster City Hall.

[16] A. Alberts, G. Baldacchino. Resilience and tourism in islands: Insights from the caribbean. tourism and resilience 12, (2017) 150.

[17] CAF. 2019. US\$200 million from CAF to improve Trinidad and Tobago roads. In

Development Bank of Latin America.

[18] PAC. 2019. Eight report of the Public Accounts Committee. In Public Accounts Committee. [19] IMF. 2016. Trinidad and Tobago selected issues International Monetary Fund, Washington, D.C.

[20] J.P. Warren, M.P. Enoch. Island transport, car ownership and use: A focus on practices in Cuba, Malta, Mauritius and Singapore. Island Studies Journal 5, (2010) 193-216.

[21] UN. 2016. Mobilizing sustainable transport for development. In United Nations.

[22] CSOTT. 2011. 2011 Census Data. In the Central Statistics Office.

[23] GovTT.1992. National integrated water management policy. In Ministry of the Attorney and Legal Affairs, 1992.

[24] A. Shashank, N. Schuurman. Unpacking walkability indices and their inherent assumptions, Health \& place 55, (2019) 145-154.

[25] P. Obst, S.G. Smith, L. Zinkiewicz. An exploration of sense of community, Part 3:

Dimensions and predictors of psychological sense of community in geographical communities. Journal of Community Psychology 30, (2002) 119-133.

[26] C. Talò, T. Mannarini, A. Rochira. Sense of community and community participation: A meta-analytic review. Social Indicators Research 117, (2014) 1-28.

[27] M. Hyde, D. Chavis, 2008. Sense of community and community building, in: Cnaan R.A., M. C. (Eds.) Handbook of community movements and local organizations, Springer, Boston pp. 179-192.

[28] M.O. Weil, Community building: Building community practice, Social Work, 41 (1996) 481-499.

[29] D. Fordham, L. Lane, K. Snyder, G. Toth, N. Stamatiadis, O. Leahu-Aluas, 2018. Using context sensitive solutions to achieve context sensitive design, State of the Practice Assessment. [30] E. Beukes, M. Vanderschuren, M. Zuidgeest, 2017. Access and mobility: Multi-modal approaches to transport infrastructure planning, in: Non-Motorized Transport Integration into Urban Transport Planning in Africa, Routledge, pp. 126-149. 
[31] K.M. MacQueen, E. McLellan, D.S. Metzger, S. Kegeles, R.P. Strauss, R. Scotti, L. Blanchard, R.T. Trotter. What is community? An evidence-based definition for participatory public health. American Journal of Public Health 91, (2001) 1929-1938.

[32] W. Williamson, K. Ruming. Can social media support large scale public participation in urban planning? The case of MySydney digital engagement campaign. International Planning Studies, (2019) 1-17.

[33] I. Gryl, D. Könen, J. Pokraka. Limits of Freedom-Defining a Normative Background for Spatial Citizenship. GI_Forum 2,(2017) 3-12.

[34] N. da Silva Lima, J.P.C. Leite, A.C. de Paiva, I.M.O. Maia, A.C. Silva, G.B. Junior, C. de Souza Baptista, 2018. Mobile application for crowdmapping accessibility places and generation of accessible Routes, in: International Conference on Applied Human Factors and Ergonomics, Springer, 2018, pp. 934-942.

[35] J. Knieling, F. Othengrafen, 2015. Crisis and urban change: reflections, strategies, and approaches, in: Cities in crisis, Routledge, London pp. 78-100.

[36] L.J. O'Toole Jr. Implementation for the real world. Journal of Public Administration Research and Theory, (2017) 376-379.

[37] P. deLeon, L. deLeon. What ever happened to policy implementation? An alternative approach. J Public Adm Res Theory 12, (2002) 467-492.

[38] J.R. Kotzebue. The EU integrated urban development policy: managing complex processes in dynamic places, European Planning Studies 24, (2016) 1098-1117.

[39] H. Bressers, N. Bressers, S. Kuks, C. Larrue, 2016. The governance assessment tool and its use, in: Governance for drought resilience, Springer, Cham pp. 45-65.

[40] J.A. Agnew, D.N. Livingstone, 2011. The Sage handbook of geographical knowledge, Sage Publications, London.

[41] R.D. Sack, 2010. Geography as a tool for developing the mind: A theory of place-making, Edwin Mellen Press, Lewiston.

[42] K. Zimmermann, P. Getimis. Rescaling of metropolitan governance and spatial planning in Europe: An introduction to the special issue. Raumforschung und Raumordnung-Spatial Research and Planning 75, (2017) 203-209.

[43] A. Nikolaeva, P. Adey, T. Cresswell, J.Y. Lee, A. Novoa, C. Temenos. A new politics of mobility: Commoning movement, meaning and practice in Amsterdam and Santiago. CUS Working Paper Series, (2017).

[44] R. Sharma, A.-R. Fantin, N. Prabhu, C. Guan, A. Dattakumar. Digital literacy and knowledge societies: A grounded theory investigation of sustainable development.

Telecommunications Policy 40, (2016) 628-643.

[45] D.W. McMillan, D.M. Chavis. Sense of community: A definition and theory. Journal of Community Psychology 14, (1986) 6-23.

[46] G. Edwards. Concepts of community: A framework for contextualizing distributed leadership. International Journal of Management Reviews 13, (2011) 301-312.

[47] M. Martiskainen. The role of community leadership in the development of grassroots innovations. Environmental Innovation and Societal Transitions 22, (2017) 78-89.

[48] M. Nakhid-Chatoor, C. Nakhid, S. Wilson, A.F. Santana. Exploring Liming and Ole Talk as a Culturally Relevant Methodology for Researching with Caribbean People. International Journal of Qualitative Methods 17, (2018). 
[49] H. Castillo, D.E. Pitfield. ELASTIC-A methodological framework for identifying and selecting sustainable transport indicators. Transportation Research Part D: Transport and Environment 15, (2010) 179-188.

[50] T. Litman. Developing indicators for comprehensive and sustainable transport planning. Transportation Research Record 2017, (2007) 10-15. 